International Journal of Advanced Studies in Humanities and Social Science (IJASHSS)

Available online at http://www.ijashss.com

Volume 8, Issue 2 (2019) pp. 178-186

Original Article

\title{
An Investigation of Protective Structure Effect on Consumers Purchase Behavior
}

\section{Eslam Nazari*1, Asgar Derakhshan², Karamat Nouri ${ }^{3}$, Saber Nazari ${ }^{4}$, Somayeh Naseramini Jelodarloo 5}

1Department of Business Management, Bilesavar Branch, Islamic Azad University, Bilesavar, Iran

2Department of Executive Management, Bilesavar Branch, Islamic Azad University, Bilesavar, Iran

${ }^{3}$ Department of Executive Management, Bilesavar Branch, Islamic Azad University, Bilesavar, Iran

${ }^{4}$ Department of English Language Teaching, Bilesavar Branch, Islamic Azad University, Bilesavar, Iran

${ }^{5}$ Department of Business Management, Bilesavar Branch, Islamic Azad University, Bilesavar, Iran

*Corresponding Author E-mail: Nazari1362mba@yahoo.com

Received: 24 October 2018, Revised: 05 December 2018, Accepted: 20 December 2018

\begin{abstract}
The final stage of all activities in marketing is to supply the needs and desires of consumers; therefore, paying attention to the market of consumption and consumers' behavior in choosing and as an important parameter in marketing and also a series of comprehensive and programmed studies and investigations must be done in order to meet their various and different needs. Product packaging, as a stimulus, is one of the parameters which can affect consumer's purchase behavior and lead them to show purchase reaction. It is packaging that can finally lead a purchaser to purchase or quite purchasing. This study is a descriptive one which has been done with the non-parametric kruskal Wallis test and $\mathrm{X}^{2}$ test. And the statistic population of this research includes 150 people from final customers of packed dates in Moghan.

Data collection in this study was through questionnaire and data has been also put into analysis with Kruskal-wallis and $\mathrm{X}^{2}$ tests. Results from this research show that protective packaging structure (weight, physical shape, type and dimension) has a significant relationship with consumers purchase behavior.
\end{abstract}

Keywords: Protective Structure, important. 


\section{Introduction}

What makes every thinker wonder is that the world population will be tow times of what is now. And this increase will be much more in third world countries than more developed and industrialized countries.

Our country is one of the major date producers in the world. According to studies by experts, capability of water and soil in the country, more than $\% 53$ of grounds in country has the capability to grow data (Amir Ghassemi, 2001).

Date grown in Iran is of the best kinds of date and is of the best quality in the world (Dasht Kian, 1987). But unfortunately Iran's date is not at the rank in the world as it deserves. Experts name some problems for this: The selection of inappropriate kinds of date, carelessness in product harvesting, advertisement, marketing (Goharian, 1996). Thus, packaging is one of our problems in date market. Packaging can be defined as following:

Packaging is a protection which maintains the safety of included product from production to consumption (Jenab, 2001). The main purpose of packaging is providing the safest and most economical approach to deliver the goods to the consumers. Packaging must be in a way that it can have both appropriate in formational and protective structure so that it can cover consumers' satisfactory on both information and product's quality. It should be known that quality marketing is all properties as product must have so that it can meet costumers' expects. Therefore, in order to boost packaging quality, it is necessary to be aware of costumer's expects so that we can produce products... and according to the expectation. But costumers expects is always increasing. So, we should always boot quality of packages (Sameer, 2011).
Date is one of the most important agricultural products in Iran and has a rather less exports than its production volume. One of the parameters involved in this issue is inappropriate packaging.

Appropriate packaging of date in a consumptive form would help country make profile in non-petroleum exports sector.

Date is an energetic meal, which can be simply preserved and stored. Until 2010, nearly 216 thousand hectors of grounds in country has been under data agriculture. The main date producing provinces in Iran are Hormozgan, Fars, Sistan and Baluchestan, Bushehr, Khuzestan, Kerman, Esfahan, Khorasan and Yazd (Amir ghasemi, 2001).

At now, 13 provinces are the date producing centers in Iran. The most northern date market in Iran is Qasre Shirin in fact; the northern limit of date agriculture in Iran is a straightforward one starts from Qasre Shirin, passes from Khur, Biabanak and Tabas in the center and ends is Birgand in East.

The southern zone of this hypothetical line is approximately the date agriculture zone in Iran (Abdollahi, 1999). In Iran, more than 4000 kinds of date can be grown, that the most important kinds are Estegmarai, Kenmelar, piarm zahedi, Diri, Sawi, Shahani, Pimaju, Moydani, Khamuyi and Mazafai. The ground under date agriculture is 203 thousand hectares and therefore date is one of the important garden products in Iran country (Amir ghassemi, 2001).

In the world, countries such as Iraq, Saudi Arabia, Tunisia, Egypt, Tanzania, Somalia and even U.S. are important date producers.

Whereas dates produced in these countries is of lower kind and quality than the date produced in Iran. 
Dates produced in Iran are cluster from and contain 18-22 percent water. They have a sage complexity and thin peel which adheres to beef of date and are without any rusts and wrinkles (Abdollahi, 1999).

Effective parameters on the quality of date are as following:

1- Plantation, cultivation and maintaining date palms

2- Careful product gathering and transportation

3- Rinsing, clearing, and sanitation of dates

4- Drying and classification of dates

5- Purchasing dates

Nowadays, consumers are under more attach from packaging than the press. Since nearly half of daily consumed goods are purchased from self-services and supermarkets which it provides one to examine products and gain in formation through packages. Human kind has been familiar with the process of conserving and storing of goods by elementary means.

Anthropological and Biomass studies show that humankind has been familiar with the packaging process from the first stage of getting food and gathering products from the ground (gathering period) and has been in the production period.

He has pondered in this case how could linger using period of foods and store the excess food following days (Niakan, 2000)

Physical properties of packages:

1. Package material /determination and awareness from properties goods to be packed such as harshness and coarseness before packaging help one use packaging materials not vulnerable when packaging such kinds of goods.

2. Packaging size (dimension)/Decision on package size cannot be successfully made without any cultural and economic examination of market. If people desire welfare conditions or have a good purchasing power, purchasing goods can be done with more appropriate packages.

3. Weight/determination of weight or density of goods is important to assign a package resistant to vertical pressure.

4. Geometrical shape/every goods, depends on its application and is identified as a specific geometrical shape, some as ordered polygons and some after in ordered polygons. However, it should be noted that there is a close relationship between shape, volume and dimension (Ampuero, 2006)

\section{Consumer's Behavior}

Consumer's purchase behavior includes various mental and social processes before and after activities about purchasing and consuming of a goods or service and indicates why people refer a product or brand to the others (Venus et al., 1997). Consumer's behavior is one of the novel issues in marketing sector. The first books in this case have been published in the 1960 's. But this issue dates back to earlier, for example the 1950's, when Fruid's opinion were used by marketers consumers behavior which is a challenging issue that includes people and what the purchase and also why and how they purchase.

Wiki and Solomon have defined consumer's behavior as following: physical, emotional and mental activities made by people when selecting, purchasing, using and discarding goods and services in order to answer their needs. In another definition consumer's behavior is as follows: a set of activities discarding goods and services. These activities include process of decisions made before and after these actions.

\section{Several Key Points about Consumer's Behavior}


Consumer's behavior is stimulated; in other words, consumer's behavior is generally in line with gaining a special goal.

\section{Consumer's Behavior Includes a Lot of Activities}

The main feature in definitions proposed for consumer's behavior is focusing on activities. Also, intestinal activities must be differentiated from stochastic activities. Some of these activities such as talking with customer and decision on shopping is international. On the contrary, sometimes, it comes up that a person enters a supermarket to purchase a good but he buys something other than what he really wanted to buy.

\section{Consumer's Behavior Is a Process}

Slection, purchase, using and discarding of goods indicates that customer's behavior is a process. Generally, the process of consumer's behavior includes three related stages of activities before shopping during shopping and after shopping activities, as well.

Behavior is focusing on activities. Also, intestinal activities must be differentiated from stochastic activities. Some of these activities such as talking with customer and decision on shopping are intentional. On the contrary, sometimes it comes up that a person enters a supermarket to purchase a good but the buy something other than what he really wanted to buy.

\section{Consumer's behavior from time viewpoint has its various complications}

Here, complication means the number of activities and difficulty with making decision to purchase. The two features i.e. time, Consuming and complication are in a direct relationship with each other, namely, assuming the other factors constant, the more complicated a decision, the more time consumed to make it.

\section{Consumer's Behavior Includes Different Roles}

At least, there are three main roles in consumer's behavior, as following: a) stimulator, b) buyer, c) consumer

\section{Consumer's Behavior Is under External Factors}

Consumer's behavior is greatly affected by external forces such as culture, reference family groups and so on.

\section{Different People Have Different Behaviors}

Different person due to individual differences shows different consuming behaviors. This is why marketer divides the market (Mive chi, 1996).

\section{Research Hypothesis}

1) There is a significant relationship between package size or dimension and date consumer's purchase behavior.

2) There is a significant relationship between package material and date consumer's purchase behavior.

3) There is a significant relationship between package weight and date consumer's purchase behavior.

4. There is a significant relationship between physical feature of packages and date consumer's shopping behavior.

\section{Methodology}

The present study is of descriptive one from survey and applicable type. The statistical population required for this research is final date purchasers and consumers in Moghan. Sampling method in this study is stepwise or classified stochastic, that is, the final date consumers in Moghan were put into consideration. The questionnaire used for this study is composed from 4 different parts (Sections one, includes individual characteristics of consumers. section one, includes 
individual characteristics of consumers. section two includes characteristics of physical services such as size, capacity and shape of package and ... goods of interest (here, date).

And section three, includes questions about the goods consumers behaviors and in section four, several brands is introduced and ranked according to consumers' views. In order to study the subject background and theoretical framework of research, library studies and electronic research sources have been used; and in order to data analysis of questionnaire, descriptive and conclusive statistics have been applied using SPSS software.

\section{Data Analysis}

The research variables are checked in terms of being normal.

\section{Test of the first hypothesis}

Hypothesis $\mathrm{H}_{0}$ : There is no significant relationship between package dimension and date consumer's purchase behavior. Hypothesis $\mathrm{H}_{1}$ : There is a significant relationship between package dimension and date consumer's purchase behavior. The average ranking and number of each package dimension has been given in Table (1), which the number of the package dimension $30 * 40$ is the most among packaging is more than others.

\section{Kruskal-Wallis Test}

Table 1. The Rankings and Number of Types of Packages in Terms of Dimension

\begin{tabular}{ccc} 
Packages & N & Mean rank \\
$30 * 40$ & 84 & 100.51 \\
$30 * 50$ & 38 & 55.05 \\
$40 * 50$ & 28 & 28.21 \\
Total & 150 & \\
\hline
\end{tabular}

Table 2. Kruskal-Wallis Test and $\mathrm{X}^{2}$ Test

\begin{tabular}{cc}
\hline & consumer's shopping behavior \\
\hline Chi-Square & 72.132 \\
Df & 2 \\
Asymp. Sig. & .000 \\
\hline
\end{tabular}

In Table (2), Kruskal Wallis test has been performed and $\mathrm{X}^{2}$ value has been calculated for it; results has been tabulated. It can be seen that the significance level (i.e. 0.000) is less than the research alpha (0.5), as a result, we can reject the hypothesis $\mathrm{H}_{0}$ with a 95\% confidence and conclude that there is a significant relationship between package type in terms of paper material and date consumer's shopping behavior.

\section{Test of the Second Hypothesis}

Hypothesis $\mathrm{H}_{0}$ : There is no significant relationship between the type of paper used for packaging and date consumer's purchase behavior.

Hypothesis $\mathrm{H}_{1}$ : There is a significant relationship between the type of paper used for packaging and date consumers purchase behavior.

In Table (3), the average ranking and number of each package in terms of the type of paper has been given. The number of package performed with white paper and nylon is more than other kinds of packaging and the average ranking assigned to the package with hard 
fiber paper and nylon is the most among the

packages listed.

\section{Kruskal-Wallis Test}

Table 3. The Rankings and Number of Types of Packages in Terms of Paper Type

\begin{tabular}{cccc}
\hline & paper type & N & Mean rank \\
\hline consumer's shopping behavior & Cardboard container with nylon cover & 26 & 85.19 \\
& white paper and nylon & 105 & 75.09 \\
& Hardfiber board with nylon cover & 10 & 101.45 \\
& Board nylon rib Without cover & 9 & 23.50 \\
& Total & 150 & \\
\hline
\end{tabular}

Table 4. Kruskal-Wallis Test and $\mathrm{X}^{2}$ Test

\begin{tabular}{cc}
\hline & consumer's shopping behavior \\
\hline Chi-Square & 18.457 \\
df & 3 \\
Asymp. Sig. & .000 \\
\hline
\end{tabular}

In Table (4), Kruskal-Wallis test was done and $\mathrm{X}^{2}$ value was calculated for it.

Results have been tabulated as can be seen; the significance level (i.e. 0.000) is lower than the research alpha (0.5). As a result, with a 95\% confident, we can reject the hypothesis $\mathrm{H}_{0}$ and conclude that there is a significant relationship between the types of package material (type of paper) in date consumer's shopping behavior.

\section{Test of the Third Hypothesis}

Hypothesis $\mathrm{H}_{0}$ : There is no significant relationship between the package weight and date consumers purchase behavior. Hypothesis $\mathrm{H}_{1}$ : There is a significant relationship between the package weight and date consumer's purchase behavior.
The average ranking and number of each type of packaging in term of weight has been given in Table 5 . As can be seen, the number of package with 500 gram capacity is more than other packaging types. And also the average ranking of assigned shopping behavior for 250 gram package is the most.

Kruskal-Wallis test was performed and $\mathrm{X}^{2}$ value for it was put into calculation. Considering the significance level of 0.000 which is lower than the research (0.5), we can reject hypothesis $\mathrm{H}_{0}$ with a confidence of $95 \%$ and conclude that there is a significant relationship between package capacity and date consumer's purchase behavior.

\section{Kruskal-Wallis Test}

Table 5. The Rankings and Number of the Types of Packaging in Terms of Capacity

\begin{tabular}{ccc}
\hline capacity & N & Mean rank \\
\hline 250 & 41 & 99.94 \\
500 & 62 & 74.32 \\
$800-1000$ & 25 & 68.04 \\
3000 & 22 & 41.75
\end{tabular}


Table 6. Kruskal-Wallis Test and $\mathrm{X}^{2}$ Test

\begin{tabular}{cc}
\hline & consumer's shopping behavior \\
\hline Chi-Square & 28.086 \\
Df & 3 \\
Asymp. Sig. & .000 \\
\hline
\end{tabular}

\section{Test of the Fourth Hypothesis}

Hypothesis $\mathrm{H}_{0}$ : There is no significant relationship between the physical feature of package and date consumer's purchase behavior.

Hypothesis $\mathrm{H}_{1}$ : There is a significant relationship between the physical feature of package and date consumers purchase behavior.

The average ranking and number of each kind of packages in terms of physical feature has been given in Table 7. As seen, the number of package with a rectangular cubic feature is the most and also the average ranking of consumer's shopping behavior assigned to the packaging with a cubic feature and sliding door is higher than other kinds of packaging listed in Table 7.

\section{Kruskal-Wallis Test}

Table 7. The Ranking and Number of Types of Packages in Terms of (Feature)

\begin{tabular}{ccc}
\hline physical shape & N & Mean rank \\
\hline Cube & 25 & 76.82 \\
Rectangular cube & 97 & 72.43 \\
Cube In the face door & 18 & 60.56 \\
Sliding Door & 10 & 128.90 \\
Total & 150 & \\
\hline
\end{tabular}

Table 8. Kruskal-Wallis Test and $\mathrm{X}^{2}$ Test

\begin{tabular}{cc}
\hline & consumer's shopping behavior \\
\hline Chi-Square & 18.437 \\
$\mathrm{df}$ & 3 \\
Asymp.Sig & .000 \\
\hline
\end{tabular}

Kruskal-Wallis test was done $\mathrm{X}^{2}$ value for it was put into calculation. As can be seen, the significance level is 0.000 lower than the research alpha (0.5). As a result, Hypothesis $\mathrm{H}_{0}$ is rejected with 95\% confidence. Therefore, we conclude that there is a significant relationship between the physical feature of packages and date consumers shopping behavior.

\section{Conclusion}

The first hypothesis: From the obtained number seen in Table 1 , it is obvious that the package dimension of $30 * 40$ has the most effect on consumers purchase behavior. Statistical results obtained using non-parametric kruskal-wall, and $\mathrm{x}^{2}$ tests show that there is a relationship between package capacity and date consumer's 
purchase behavior. As mentioned earlier, decision on package dimension cannot be successfully med without considering cultural and economic features of market even though people are in a welfare condition or have a good purchasing power, and/or due to the short period of purchasing, people tend to purchase products in appropriate dimensions for transportation. Appropriate package dimensions can have positive effect on transportation, and storage of date and selection of an appropriate date package can positively affect date quality which, in turn, has an important effect on consumers purchase behavior and increase the purchase behavior of consumers. In the present research, the package dimension of $30 * 40 \mathrm{~cm}$ is the most appropriate. Therefore, the greater the package dimension, the less the purchase behavior. The second hypothesis: As comes from numbers in Table 3, the most occurring purchase behavior is about packaging with white paper and nylon, as statistical results shows (degree of freedom of three an alpha level of $0.5, x^{2}$ value of 18.45 which are more than other kind of packaging. According to kruskal-Wallis test, it can be said that there is a relationship between package material (paper type) and date consumers purchase behavior.

The third hypothesis: From the numbers in Table 5, packaging capacities of $250 \mathrm{~g}$ and $500 \mathrm{~g}$ are best seller. Packages of date statistical results using nonparametric kruskal-wallis test and $\mathrm{x}^{2}$ test show that with a confidence level of $95 \%$ there is a relationship between package capacity and date consumer's purchase behavior. Determination of the weight of density of goods in selection of a package is because of predicting the extent to which a package can resist the pressure entered its bottom. The more the capacity of a package, the less date consumers purchase it. Maybe, one of the main reasons for this issue is dates of low quality packaging in such packs.

Test of the fourth hypothesis: Hypothesis $\mathrm{H}_{0}$ : There is no significant relationship between the physical feature of package and date consumer's purchase behavior. Hypothesis $\mathrm{H}_{1}$ : There is a significant relationship between the physical feature of package and date consumers purchase behavior.

As a result, Hypothesis $\mathrm{H}_{0}$ is rejected with 95\% confidence. Therefore, we conclude that there is a significant relationship between the physical feature of packages and date consumers shopping behavior.

\section{References}

Abdollahi, A. (1999) Export date, number 244, p: 45-54.

Amir Ghasemi, T. (2001)."Role strategic dates in economy country"p: 65, publication sable, number102.

Ampuero. O. Vila N. (2006). consumer perceptions of product packaging - journal of consumer marketing - pp.100-112

Dashate kiyan, S. (1987)."Scrutiny product date in Iran" Deputy sugar industryMinistry of industry p: 15.

Gohariyan, M.E. (1996) Management exports propagation institution (cover 1)Institute of commercial studies and research publications, p:322 -328.

Ganab, B. (2001) Order than designer (industry and package).

Mivechi, M. (1996), Packaging staple alimentary, Industry and safety, number 92, p: 28-34. 
Niyakan, D. (2000)."Cardboard packaging and its benefits". Edition and packaging, number22, p:31-32.

Stay and solutions", Olive publication, number52, p: 52-54.
Venuse. Davar, A. Ahmad, ebrahimi A. (1997), Management),advertise side,p:212.

(Marketing

sameer K. (2011). A global supplier selection process for food packaging. p: 247.

How to cite this article: Eslam Nazari, Asgar Derakhshan , Karamat Nouri, Saber Nazari, Somayeh Naseramini Jelodarloo, An Investigation of Protective Structure Effect on Consumers Purchase Behavior. International Journal of Advanced Studies in Humanities and Social Science, 2019, 8(2), 178-186.

http://www.ijashssjournal.com/article 84356.html 